but merely different phases of one life-history, the lake fish being slimy and dark and the sea fish clean and shining blue. On the east coast there is a continuous movement from the southern rivers into those north of them, and there must be recruitment from the north as there are apparently no separate races, and there is probably one intermingling stock. Thus the problem is one for a single uniform policy.

The mullet is a bottom feeder and eats the sandy and muddy slime of the fresh and brackish waters, taking in the organic substances in it. Presumably, feeding ceases when the fish move to the sea. The larval development is unknown, but there are reasons to believe that the egg is pelagic and hatches within a short period, spawning probably occurring at or near the mouths of the estuaries in the surf zone. The young fish are still within a few miles of the estuary at the end of the first year, but after that they move farther up the rivers or lakes and spend their second and third year there.

\section{NEW ZEALAND EARTHQUAKES DURING 1941}

A CCORDING to the report on seismology for the year ended December 31, 1941, which has recently been received from the acting director, R. C. Hayes, the total number of earthquakes reported felt in New Zealand during 1941 was 107 , the smallest number in any year since 1928 (Dominion Observatory Bulletin No. R.27, extracted from the Annual Report of the Department of Scientific and Industrial Re. search, 1941-42, Dominion Observatory, Wellington, New Zealand). The earthquakes, in addition to being reported by numerous individuals as having been felt, were recorded by instruments as follow, the situation of the instrument being given first, and the type of instrument in parenthesis afterwards: Auckland (Milne-Shaw), Arapuni (Milne), Rotorua (Jaggar), Tuai (Wood-Anderson), New Plymouth (Wood-Anderson), Hastings (Jaggar), Bunnythorpe (Jaggar), Wellington Central Station (Galitzin-Wilip, Milne-Shaw, Wood-Anderson, Jones, Imamura), Takaka (Imamura), Greymouth (Jaggar), Christchurch (Galitzin three components, Wood-Anderson), and Monowai (Jaggar). Milne-Shaw seismograph No. 36 was installed at the Auckland Museum early in April. However, it was not until November that the necessary apparatus was obtained for maintaining accurate time. There was considerable delay in establishing a Wood-Anderson seismograph at Kaimata near Greymouth owing to the war, but some progress has been made. The public works officials at Rotorua have developed a method of obtaining records on blueprint paper instead of on smoked cardboard. The seismograph at Chatham Islands has been temporarily suspended owing to the War.

Of the 107 shocks in 1941,61 were felt in some part of the North Island and 55 in some part of the South Island. Nine were felt in both Islands. The maximum intensity reported felt was Rossi-Forel (R.F.) 8. Although the number of shocks felt was small, seismograph records indicate that minor activity was much the same as in previous years. Earthquakes were comparatively frequent in the far north-eastern part of the North Island and in the central districts; and there was more activity than usual in Canterbury. On the other hand, most of
Hawke's Bay was comparatively free from earthquakes. Occasional shocks originated in the far southwest. The only two outstanding seismic events occurred early in the year. These were (1) a shock of $R . F .8$ orjginating near Taneatua, in the Bay of Plenty, on January 9 ; and (2) one of R.F. 6-7 near Lake Coleridge, in Canterbury, on February 7. The Taneatua shock was of very shallow origin, and in spite of the high intensity in the epicentral region the maximum radius of the 'felt' area did not exceed 70 miles. The Lake Coleridge shock was of normal depth and its 'felt' area was also small (maximum radius about 100 miles). After-shocks of the Lake Coleridge disturbance continued at intervals throughout the remainder of the year. Both these earthquakes were approximately 5 on the instrumental magnitude scale. Other shocks with $R . F$. intensity 6 or greater than 6 were: April 6d. 18h. 46.8m. U.T. from Taumarunui and Hastings to Queenstown and Dunedin (6), May 29d. 11h. 17.1m. U.T. parts of southern Hawke's Bay $(6+)$, August 10d. 10h. 05.2m. U.T. Southland, parts of Otago (6), and September 24d. Ilh. 39.5m. U.T. Opotiki to Wanganui and Waipawa (6). Four further shocks had scale 5 or rather greater, and one had scale 3 intensity.

Two notable features of the 1941 results were: (1) a prevailing tendency for activity to be concentrated towards the north-western side of the general seismic region; and (2) the occurrence of shocks slightly deeper than normal in the submarine region between Taranaki and Nelson and beneath the northern part of the South Island. This has been confirmed by a recent revision of the earthquake records of previous years.

\section{NUTRITION IN RELATION TO BONE GROWTH AND THE NERVOUS SYSTEM}

7 HE problem had its origin in observations made in 1918, when an experimental study of rickets was in progress. Some of the animals developed severe inco-ordination of movement, independently of rickets; and the condition clearly involved a different etiological factor. The latter differentiation of the anti-rachitic vitamin from vitamin $A$ made it. possible to show that the inco-ordination of movement in young animals was due to vitamin A deficiency.

Examination of the peripheral and central nervous system revealed widespread degeneration of afferent nerves (cranial and spinal) and ascending fibres in the central nervoús system. The interpretation of the results at this period was that vitamin A deficiency produced degenerative changes in most nerve cells of afferent and ascending nerves, but left those of the descending and efferent nerves intact. Here the position was left for some years, but the unsatisfactory nature of the explanation impelled a return to the investigation. Since the 8 th nerve was obviously particularly affected, serial sections of the labyrinthine capsules were studied. This examination led to the finding of abnormal bone growth in. the internal auditory meatus, which was clearly pressing on both divisions of the 8th nerve. A similar

* Substance of the Croonian Lecture delivered by Sir Edward Mellanby, K.C.B., F.R.S., before the Royal Society on July 15. 